\title{
A TRAJETÓRIA DA POLÍTICA HABITACIONAL A PARTIR DA PERSPECTIVA DO INSTITUCIONALISMO HISTÓRICO
}

\section{THE TRAJECTORY OF HOUSING POLICY FROM THE PERSPECTIVE OF THE HISTORICAL INSTITUTIONALISM}

\author{
Gabriel Moraes Outeiro ${ }^{1}$ \\ Durbens Martins Nascimento ${ }^{2}$
}

\section{RESUMO}

Esta pesquisa tem como objetivo examinar a coordenação de interesses na trajetória da política habitacional federal desde a década de 1940. Nesse contexto, questiona qual o legado deixado por essa trajetória para a política habitacional no espaço urbano brasileiro, que inicia com a Fundação da Casa Popular, passa pelo Banco Nacional da Habitação em 1964 até chegar no programa Minha Casa Minha Vida em 2009. Assim, o trabalho utiliza como arcabouço teórico o institucionalismo histórico, que orienta a sua abordagem metodológica, que examina o comportamento dos atores, a trajetória institucional e o seu legado. Trata-se de pesquisa qualitativa, que se utilizou de pesquisa bibliográfica e documental. Como principal resultado, constatou-se que a dinâmica políticoinstitucional da política habitacional iniciou um caminho mais direcionado a estimular a economia do setor da construção civil, do que atender às camadas sociais mais vulneráveis, setor esse que se manteve relativamente estável dentro do quadro federativo, reproduzindo segregação socioespacial e sem condições de efetivar o direito à cidade em favor de todos os moradores do tecido urbano.

Palavras-chave: Institucionalismo histórico. Política habitacional. Reforma Urbana. Banco Nacional da Habitação. Programa Minha Casa Minha Vida.

\section{ABSTRACT}

This research aims to examine the coordination of interests in the trajectory of federal housing policy since the 1940s. In this context, it questions what legacy this trajectory has left for housing policy in the Brazilian urban space, that starts with the 'Popular House Foundation', passes through

\footnotetext{
${ }^{1}$ Doutor em Desenvolvimento Socioambiental pelo NAEA/UFPA. Diretor-Geral do Instituto de Ciências Sociais Aplicadas da Universidade Federal do Sul e Sudeste do Pará - ICSA/Unifesspa. Universidade Federal do Sul e Sudeste do Pará/Universidade Federal do Pará - Brasil. E-mail: gmouteiro@gmail.com

2 Doutor em Desenvolvimento Socioambiental pelo NAEA/UFPA. Pesquisador do NAEA/UFPA. Cientista político. Universidade Federal do Pará - UFPA - Brasil. lattes: h ttp://lattes.cnpq.br/4086120226722277 ORCID iD: http://orcid.org/0000-0002-8118-5152

E-mail: durbens.naea@gmail.com
} 
the National Housing Bank in 1964 until arriving at the 'My house, my life' program in 2009. Thus, the work uses historical institutionalism as a theoretical framework, which guides its methodological approach, which examines the behavior of the actors, the institutional trajectory and their legacy. It is a qualitative research, which used bibliographic and documentary research. As a main result, it was found that the political-institutional dynamics of housing policy started a path more directed at stimulating the economy of the civil construction sector - than at serving the most vulnerable social strata - which remained relatively stable within the federative framework, reproducing socio-spatial segregation and unable to enforce the right to the city in favor of all residents of the urban fabric.

Keywords: Historical institutionalism. Housing policy. Urban Reform. National Housing Bank. Minha Casa Minha Vida Program.

\section{1 - INTRODUÇÃO}

O processo de formação e de crescimento das cidades brasileiras ao longo do século XX acentuou as desigualdades sociais, com base em um modelo de desenvolvimento urbano que privou as faixas de menor renda da população de condições básicas de urbanidade ou de inserção à cidade (ROLNIK, 2009).

Neste paradigma de desenvolvimento, a habitação se revela como uma necessidade fundamental dos seres humanos, ao mesmo tempo em que é bem de consumo, o que levou o Estado, a partir da década de 1940 a adotar medidas governamentais neste setor e, consequentemente, uma série de atores se mobilizou na pretensão de influenciar as decisões estatais sobre as políticas públicas de habitação (KLINTOWITZ, 2015, p. 68). Ou seja, a moradia é ao mesmo tempo uma necessidade e uma mercadoria de consumo privado (MARICATO, 1998). Neste contexto, o trabalho questiona qual o legado deixado por esta trajetória para a política habitacional no espaço urbano?

Neste sentido, este trabalho tem por objetivo examinar a coordenação de interesses na trajetória da política habitacional desde a década de 1940. A política habitacional tem tido por escopo enfrentar a crise de moradia em um país que se urbanizava sem planejamento desde o século passado (BONDUKI, 2008). 
A literatura tem analisado a política habitacional no contexto de Reforma do Estado (KLINTOWITZ, 2011), a coordenação de interesses de diferentes atores, com agendas distintas, em torno da politica habitacional brasileira (KLINTOWITZ, 2015), os modelos teóricos de análise da política habitacional no Brasil (NASCIMENTO NETO, et al, 2015), a articulação da questão fundiária na política habitacional (MOREIRA; RIBEIRO, 2016), ou ainda, de forma mais específica, os atores e arenas envolvidos em investimentos habitacionais no Estado de São Paulo (ROLNIK; IACOVINI; KLINTOWITZ, 2014).

Assim, constatou-se que apesar de que existem trabalhos que adotam o prisma institucional para analisar a política habitacional brasileira entre os anos 2000 (KLINTOWITZ, 2015), há uma lacuna na literatura científica em trabalhos que examinam a origem das políticas na habitação usando a teoria institucional. A visão institucional contribui na análise dos fatores de bloqueio da mudança, que reproduzem no presente escolhas políticas feitas no passado, ainda que ineficientes, o que pode oferecer novos insights sobre a política habitacional.

A pesquisa utilizou contribuições do referencial do institucionalismo histórico, que considera a análise dos atores e seus interesses no estudo das políticas públicas (HALL; TAYLOR, 1996). As instituições são variáveis que podem explicar diferenças de qualidade de vida e de crescimento econômico entre países e regiões, que são influenciadas pela relação de forças que se estabelece entre burocracias estatais e atores, ao mesmo tempo em que exercem influência no comportamento destes agentes.

Trata-se de pesquisa com abordagem qualitativa, que se utilizou de pesquisa bibliográfica e documental. Como fonte secundária, foram estudados documentos oficiais e institucionais disponíveis na rede mundial de computadores.

Espera-se que essa pesquisa poderá contribuir para a formulação de políticas públicas na área habitacional pelos atores políticos, tendo condições de ser base para outros estudos na esfera acadêmica.

\section{2 - O INSTITUCIONALISMO HISTÓRICO COMO ABORDAGEM PARA O ESTUDO DE POLÍTICAS PÚBLICAS DE HABITAÇÃO}

A partir da década de 1930, os países que adotavam o sistema de economia de mercado passaram a organizar suas estruturas estatais para desenvolver políticas sociais como educação, 
saúde e habitação, dando forma a um tipo de organização política e econômica, que ficou conhecida como Estado de Bem-estar Social, em que o Estado assume a responsabilidade pelo bemestar dos seus cidadãos e pela proteção social da sociedade.

Esse tipo de organização exigia aparatos burocráticos e volume de recursos públicos para dar conta das demandas sociais, de forma que o Estado passa a regular e a influenciar diversos aspectos da vida social por meio de políticas. Tendo como pressuposto analítico de que a ação governamental pode ser formulada cientificamente e analisada por pesquisadores independentes (SOUZA, 2006), consolida-se o estudo de políticas públicas, que tem origem nos Estados Unidos. A análise de política pública desponta como forma de conciliar conhecimento científico com a produção empírica dos governos e estabelecer o diálogo entre grupos de interesse e o governo (LASWELL, 1936).

Nesta seara, a análise de políticas públicas é, por definição, o exame do governo em ação para alcançar objetivos em relação a um determinado problema (GÖTTEMS, et al., 2009). O enfoque institucional para a análise se deve ao fato de ser uma ferramenta que considera os atores, seus interesses e o desenho político-institucional, a partir de uma perspectiva histórica.

A possibilidade de aplicação da teoria institucional à política habitacional emerge da questão da moradia passar a ser problema de política pública (SANTOS; DUARTE, 2010), tendo sido reconhecida como um direito humano, indispensável à vida digna de qualquer ser humano, desde 1948, ao ser inscrito na Declaração Universal de Direitos Humanos (OUTEIRO; NASCIMENTO, 2016).

Assim, uma moradia digna não se resume à habitação ou abrigo, abrangendo a proteção legal do imóvel, infraestrutura, considerando a localização da residência (OUTEIRO; NASCIMENTO, 2016), o que faz com o Estado tenha que agir, por meio de políticas públicas, para efetuar a gestão do solo em favor da promoção da inclusão social (OUTEIRO, 2019).

Segundo Peres (2008), é possível encontrar estudos institucionais desde a análise das constituições atenienses com Aristóteles. Entretanto, é o economista norte-americano Veblen (1989) com sua tese sobre instinto, hábito e instituição, que é considerado um dos fundadores do institucionalismo enquanto um programa de pesquisa (SILVA, 2010).

Ocorre que este programa de pesquisa, denominado como antigo institucionalismo, ao realizar a análise de políticas públicas, considerava as mudanças nas suas regras e programas como uma mera reavaliação estatal, por ter ocorrido algum problema na sua implementação. A concentração em abordagens formais causou o declínio do antigo institucionalismo como vertente 
teórica apta a explicar fenômenos, como as crises do liberalismo e de representação e a alienação política (PERES, 2008).

Com base naquelas inquietações, já na década de 1970, o institucionalismo norteamericano ganha fôlego, ao incorporar a consideração do comportamento individual, a ponto de diversos autores considerarem que surgiu um novo institucionalismo ou também chamado neoinstitucionalismo (HALL; TAYLOR, 1996; MARCH; OLSEN, 1984).

Nessa linha de raciocínio, as instituições podem ser vistas como arenas em que ocorrem os processos fundamentais do jogo político, cujos estudiosos se voltam para a análise individual e de interesses em conflito e questões empíricas (MARCH; OLSEN, 1984). O conceito de instituição, entretanto, não é unânime, sendo por vezes compreendido como o conjunto das organizações e das regras que define os padrões de interação que possibilitam a consolidação das estruturas (OSTROM, 2007), ou, por vezes, apenas as regras de determinada arena decisória que influenciam o comportamento dos atores (STEINMO, 2008), que podem ser apenas as regras formais ou incluir as informais, como costumes e cultura, a depender do autor (HALL; TAYLOR, 1996). Logo, apesar da divergência, há um núcleo rígido que envolve as regras que exercem algum nível de coerção sobre os indivíduos da sociedade.

Na perspectiva neoinstitucionalista, as instituições moldam a ação humana, que em diferentes momentos da história decide em favor de uma determinada política, em face de uma série de fatores, iniciando uma trajetória difícil de ser alterada posteriormente. Para Hall e Taylor (1996), é possível identificar, pelo menos, 3 vertentes teóricas do neoinstitucionalismo, que são o institucionalismo histórico, institucionalismo da escolha racional e o institucionalismo sociológico.

Segundo Immergut (1998), existem premissas epistemológicas que constituem um núcleo teórico que une as três abordagens, como o fato de que as três consideram que preferências expressas não devem ser confundidas com preferências reais de uma pessoa; e que decisões coletivas não podem se fundamentar na agregação de preferências individuais, o que permite a tomada de decisões políticas onde não há consenso aparente, pois as instituições redefinem as preferências dos agentes políticos, reduzindo o leque de escolhas.

Ocorre que para o institucionalismo da escolha racional os indivíduos são seres racionais estratégicos, que calculam custos e benefícios no momento de suas decisões para maximizar seus ganhos pessoais (STEINMO, 2008), sendo que as instituições organizam as opções disponíveis aos indivíduos que cooperam entre si porque ganham mais em conjunto do que sozinhos (HALL; TAYLOR, 1996). 
Por outro lado, o institucionalismo sociológico emerge dentro da teoria organizacional, para compreender as formas pelas quais as organizações modernas estruturam suas atividades cotidianas, ainda que não sejam eficientes, o que levou estudiosos a argumentarem que os procedimentos e regras institucionais eram adotados porque representavam a expressão de práticas culturais (HALL; TAYLOR, 1996). Nesta vertente os indivíduos são seres sociais (STEINMO, 2008) e as instituições moldam a forma como as pessoas veem o mundo (THÉRET, 2003), limitandoas cognitivamente (IMMERGUT, 1998).

Por fim, o institucionalismo histórico está ligado aos referenciais pluralistas e estruturalfuncionalistas, proeminentes na Ciência Política entre os anos de 1960 e 1970, que encontrou nas instituições a resposta para os conflitos na economia e na política (HALL; TAYLOR, 1996), que se coloca num meio-termo entre o institucionalismo da escolha racional e o sociológico (IMMERGUT, 1998).

Assim, as instituições moldam o comportamento individual e reduzem incertezas, conectando as estruturas sociais e o comportamento individual de atores que buscam maximizar seus interesses, cujos padrões cognitivos são construídos pela tradição (STEINMO, 2008). Logo, as preferências são constituídas socialmente e as instituições são regras formais e informais, que configuram estrutura política.

Segundo Immergut $(1998 ; 2006)$, no institucionalismo histórico os processos políticos são estruturados pela Constituição e por instituições políticas, pelo Estado e suas relações com grupos de interesse, redes de políticas e contingências de timing.

\section{1 - Institucionalismo Histórico}

Nesta vertente, a origem das instituições está relacionada com a dinâmica de estruturação das relações de poder em uma comunidade política (STEINMO, 2008), o que permite reflexões e insights que não considerados nos outros eixos teóricos, tornando o institucionalismo histórico mais adequado para o exame das políticas habitacionais.

Os institucionalistas históricos se ocupam do exame de configurações organizacionais, transformação estrutural e processos de longo prazo, o que evidencia os processos de interação que definem (e redefinem) o Estado, o jogo político e o resultado de políticas públicas (SKOCPOL; PIERSON, 2002). 
Em um sentido amplo, é uma abordagem que ilustra como o jogo político é mediado pelas instituições que exercem influência na conduta individual (SOTO, 2016). Seu enfoque permite considerar as assimetrias de poder no desenvolvimento institucional (HALL; TAYLOR, 1996).

No que tange ao recorte metodológico, os institucionalistas históricos utilizam enfoques narrativos para construir explicações históricas baseadas em abordagens qualitativas e métodos interpretativos (SOTO, 2016), que na análise de políticas públicas vai considerar os momentos singulares de decisão de atores políticos, que disputam recursos escassos, cujas escolhas terão efeitos ao longo do tempo.

As instituições, no sentido atribuído por Steinmo (2008), de um conjunto de regras de determinada arena decisória, irão influenciar os atores que atuam naquele jogo. A herança institucional é vista como um legado que emerge de conflitos históricos (THELEN, 1999), no sentido de que após o início de um caminho, os custos para reverter o rumo são altos, pois a despeito da existência de novos pontos de escolha, os arranjos institucionais tendem a autorreforçar a escolha inicial.

Portanto, ao se reconhecer que a trajetória de um país ou região importa, o resultado é que a história importa, o que dificulta copiar soluções políticas prontas de países ou regiões com trajetória diferente. Estes dois temas, persistência das instituições passadas e mudança institucional, entraram na pauta do neoinstitucionalismo.

Ocorre que as instituições influenciam o comportamento, mas não são elas que definem o desfecho do jogo, pois são criadas e modificadas pelo ser humano. Nesse passo, outros aspectos, como desenvolvimento socioeconômico, acesso a recursos naturais, nível de tecnologia disponível, podem alterar os resultados, tratando-se de um mundo mais complexo do que aquele em que existe apenas preferências individuais e instituições. Este quadro conduz a um conceito central para os institucionalistas históricos, denominado path dependence, que destaca a questão do tempo e a sequência das ações desenvolvidas (IMMERGUT, 2006)

\section{2 - Path Dependence}

Os estudiosos deste eixo teórico não se resumem às observações sobre o passado, pois o que é mais pertinente é a percepção de processos ao longo do tempo (SKOCPOL; PIERSON, 2002). Em suma, a ênfase é dada ao encadeamento de fatos e acontecimentos, em que as instituições são 
produtos concretos da passagem do tempo, que emergem dentro de um contexto político e social, por vezes com efeitos indesejados e nem sempre é coerente (THELEN, 2006).

Para Capoccia (2016) é possível ver o jogo político como arenas de conflito, nas quais atores (como políticos, cidadãos, escolas, empresas) vão competir para que as instituições reflitam seus interesses e agendas. Como existem atores que possuem algum tipo de poder político, ou que conseguem maximizar suas preferências na moldura institucional existente, eles irão bloquear mudanças que os prejudique, tornando a trajetória dependente do caminho inicialmente trilhado.

Ou seja, de forma endógena, é difícil permitir uma mudança institucional abrupta, pois são criados mecanismos autorreforçantes no jogo político, que permitem apenas ajustes incrementais. Com efeito, antes, as instituições são mantidas por processos endógenos, por intermédio de lógicas de conveniência ou econômica, que dependem de poder político, que garantem um fluxo de recursos para determinados grupos.

Logo, Capoccia e Kelemen (2007) ensinam que os principais responsáveis pela manutenção das instituições são atores relevantes, que passam a ajustar suas estratégias para se acomodar ao novo padrão vigente e dificultam mudanças que possam lhes prejudicar.

Por isso, as instituições não são compreendidas se forem isoladas do seu contexto político e, apesar da trajetória dependente endossar a continuidade, há abertura para mudanças (THELEN, 2006). O que não deixa de representar uma contradição em termos, pois as instituições asseguram certa estabilidade à sociedade, mas, em alguns casos, permitem a mudança (MACEDO; CKAGNAZAROFF, 2018).

Ademais, conhecimento técnico, que costuma contribuir para formular leis urbanas e políticas habitacionais, não é suficiente para abarcar a complexidade das decisões políticas, principalmente se isolados do embate político que engendra essas escolhas (ANITELLI; TRAMONTANO, 2016).

Deste modo, apropriando-se dos instrumentos do institucionalismo histórico, é possível conceber um modelo de análise da política habitacional.

\section{3 - PROPOSTA METODOLÓGICA: ARTICULAÇÃO dOS FATORES EXPLICATIVOS DA POLÍTICA HABITACIONAL}


A análise da dinâmica político-institucional da política habitacional foi realizada a partir de um modelo que incorporou as categorias analíticas do institucionalismo histórico. Para iniciar sua elaboração, primeiro foram sistematizados os principais conceitos da abordagem neoinstitucional histórica, como pode se observar no Quadro 1.

Quadro 1. Principais conceitos do Institucionalismo Histórico.

\begin{tabular}{|c|l|}
\hline Elementos & \multicolumn{1}{|c|}{ Conceito } \\
\hline Instituições & $\begin{array}{l}\text { Conjunto de regras, formais e informais, de } \\
\text { determinada arena decisória, que influenciam } \\
\text { o comportamento dos atores }\end{array}$ \\
\hline \multirow{3}{*}{ Interesses } & $\begin{array}{l}\text { As interpretações dos atores de seus interesses } \\
\text { são moldadas por organizações coletivas e } \\
\text { instituições que carregam traços da própria } \\
\text { história }\end{array}$ \\
\hline Processo político & $\begin{array}{l}\text { Processos políticos estruturados por } \\
\text { Constituição e instituições políticas, estruturas } \\
\text { de Estado, relações entre Estado e grupos de } \\
\text { interesse, redes de políticas e contingências de } \\
\text { timing de }\end{array}$ \\
\hline Atores & $\begin{array}{l}\text { Individuais ou coletivos, autorreflexivos } \\
\text { Pepende do reconhecimento pelo Estado, do } \\
\text { acesso à tomada de decisões, da } \\
\text { representação política e das construções } \\
\text { mentais }\end{array}$ \\
\hline
\end{tabular}

Fonte: Adaptado de Immergutt (1998) e Steinmo (2008).

A ideia é permitir visualizar alguns conceitos importantes para o institucionalismo, para permitir sua aplicação à política urbana, com os devidos cuidados apontados na seção anterior, incluindo que algumas definições não encontram unanimidade na doutrina especializada. No entanto, tais concepções permitem avançar para sistematizar noções e elaborar tipologias de estudo.

Então, a partir destes conceitos foi uma construída uma matriz analítica em três dimensões - contexto estatal; trajetória e institucionalidade da descentralização da política urbana; e condicionantes desses processos - cujas definições e componentes encontram-se especificados no Quadro 2, que teve como base a proposta de análise institucional da política de saúde de Pereira, Lima e Machado (2018), que permite considerações abrangentes sobre diversos fatores.

Quadro 2. Matriz de análise para o estudo da política habitacional. 


\begin{tabular}{|c|l|l|}
\hline $\begin{array}{c}\text { Dimensões de } \\
\text { análise }\end{array}$ & \multicolumn{1}{|c|}{ Definições } & \multicolumn{1}{|c|}{ Componentes de Análise } \\
\hline Contexto & $\begin{array}{l}\text { Contexto de distribuição do poder do } \\
\text { Estado no âmbito das políticas } \\
\text { públicas }\end{array}$ & $\begin{array}{l}\text { Contexto político } \\
\text { Contexto econômico }\end{array}$ \\
\hline $\begin{array}{c}\text { Trajetória da } \\
\text { política } \\
\text { habitacional }\end{array}$ & $\begin{array}{l}\text { Processo de implementação da da } \\
\text { política habitacional, marcado por } \\
\text { regras formais }\end{array}$ & $\begin{array}{l}\text { Desenho institucional da Política } \\
\text { Elementos de continuidade e de } \\
\text { mudança }\end{array}$ \\
\hline Condicionantes & $\begin{array}{l}\text { Elementos do contexto que exercem } \\
\text { influência na trajetória }\end{array}$ & $\begin{array}{l}\text { Fatores políticos, institucionais e } \\
\text { econômicos } \\
\text { Papel das instituições e dos atores } \\
\text { Estratégias de atuação das } \\
\text { instituições e dos atores }\end{array}$ \\
\hline
\end{tabular}

Fonte: Adaptado de Pereira, Lima e Machado (2018).

De posse destas informações, será possível analisar o contexto de distribuição do poder do Estado em cada período da política habitacional federal, conforme se dão os fatores políticos e econômicos, a trajetória da política habitacional com seus elementos de continuidade e de mudança e as condicionantes que exerceram influência no rumo seguido.

Deste modo, foi um concebido um modelo teórico de análise, para permitir considerações sobre a política habitacional que podem ser ignoradas por outras vertentes de estudo das políticas públicas com dados coletados a partir de pesquisa bibliográfica e documental. As reflexões teóricoconceituais e as observações empíricas preliminares do fenômeno permitiram estabelecer critérios de exame, e construir um modelo de estudo, como se observa na Figura 1.

Figura 1. Modelo de análise da política habitacional 


\section{Trajetoria institucional da polltica habitacional}

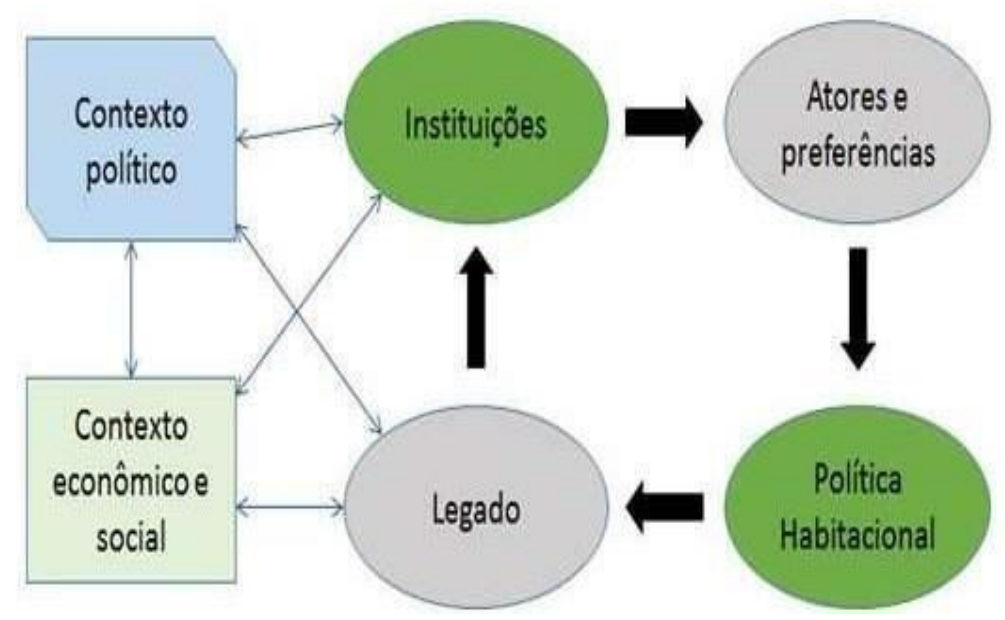

Fonte: Elaborado pelos autores, 2020.

A proposta do trabalho é analisar, sob o enfoque institucional, a política habitacional desde 1940, de forma interdisciplinar e integrada. Neste sentido, será verificado como o contexto político e econômico influenciam as instituições, que por sua vez moldará a atuação dos agentes, para desenhar a política habitacional e, consequentemente, deixar um legado.

Estes elementos de continuidade e de mudança serão condicionados, novamente, por fatores políticos, institucionais e econômicos que irão modelar novas instituições, como novas regras ou novos programas, que consequentemente, não devem representar mudanças abruptas da escolha original.

\section{4 - A POLÍTICA HABITACIONAL FEDERAL}


A compreensão da política habitacional exige algumas considerações sobre fatores históricos, que em conjunto contribuem para a visualização do contexto e da atuação dos atores no marco institucional vigente, ainda que dentro do limite temporal de análise definido neste trabalho, que inicia em 1940.

Com efeito, o estudo da história da política habitacional mostra avanços na formulação e implementação de políticas públicas, sobretudo no que se refere à implementação da agenda da reforma urbana, mas também evidencia problemas e contradições (BONDUKI, 2016, p. 79).

Na década de 1930, o Brasil experimenta o regime político do Estado Novo, da Era Vargas, com centralização do poder político e econômico na União. Até 1930, as medidas governamentais concernentes à habitação popular não consideravam a melhoria das condições de residência das classes de baixa renda como seu principal objetivo, mas a partir deste período as políticas destinadas aos setores populares procuram aumentar a margem de legitimidade do Estado, que percebe na habitação a possibilidade de ganhos políticos (AZEVEDO, 1988).

É nesse contexto em que estão as primeiras intervenções públicas na área de habitação popular no âmbito federal, pois não havia uma política de planejamento urbano desenhada pela União, mas sim planos de desenvolvimento.

A criação da Fundação da Casa Popular (FCP), em 1946, num período de redemocratização e final da Era Vargas, representa a primeira organização de nível nacional voltada exclusivamente para a construção de casas para as classes de baixa renda por meio de subsídios, mas que teve problemas de financiamento por depender principalmente do orçamento federal e, a despeito de sua finalidade institucional, acabou beneficiando pessoas que possuíam algum tipo de influência política (AZEVEDO, 1988). O resultado é que as decisões sobre os investimentos foram influenciadas por interesses pessoais de autoridades do governo federal ou de pessoas da própria organização. Neste período se inicia a indução acelerada da industrialização.

Este contexto permite compreender a complexidade que permeia a política habitacional. A habitação é uma necessidade básica de todo ser humano, que precisa de um lugar para repousar, sozinho ou com seus pares. O reconhecimento de sua essencialidade fez com que fosse reconhecida como um direito fundamental, previsto no art. 6 da Constituição de 88.

Acontece que a habitação também é um bem de consumo privado (MARICATO, 1998), o que transfere o protagonismo na tomada de decisões nesta área ao mercado imobiliário. Neste contexto em que a habitação é um direito social e, ao mesmo tempo, mercadoria, um conjunto de 
atores se mobilizou no Brasil para influenciar as decisões estatais sobre as políticas públicas de habitação ao longo do séc. XX.

Numa sociedade dividida em classes sociais, a luta pelo direito à cidade envolve pensar como a cidade é produzida de maneira desigual, para alcançar o direito à cidadania, à vida na cidade (COSTA, 2017, p. 755). Para Lefebvre (2001) a cidade deve ser desfrutada por todas as classes sociais, pois possui a capacidade de acumular riquezas e de reunir conhecimento, técnicas e obras, porém que tem sido transformada em mero valor de troca ou mercadoria.

Nesse passo, a década de 1960 foi marcada pelo início da ditadura militar, instaurada em abril de 1964, sob o comando de governos que se estenderam até março de 1985. Com a expansão da população urbana houve a necessidade política de elaboração de uma proposta de intervenção no espaço, momento em que foi criado o Banco Nacional da Habitação (BNH) em 1964, herdeiro da FCP, extinta pela Lei n. o 4.380/1964, com a finalidade de subsidiar a produção de empreendimentos imobiliários, disponibilizando crédito com juros subsidiados para companhias públicas de saneamento e de habitação.

Neste período, o Estado adotou políticas públicas anticíclicas e na intenção de estreitar os laços entre economia brasileira e o capital internacional, diversas reformas foram implementadas, dentre as quais estão a bancária (Lei n. o 4.595/1964); a habitacional, criando o Sistema Financeiro de Habitação (SFH) (na citada Lei n. ⒋380/1964); e a do Sistema Financeiro e do Mercado de Capitais (Lei n. o 4.728/1965) (COSTA, 2017, p. 761-762). Não havia espaço para discutir ideias, pois a tendência era ocultar conflitos e construir o consenso à força (MARICATO, 1998)

O BNH já foi instituído em moldes empresariais, combinando receita própria e captação de poupança, voluntária (caderneta de poupança) e compulsória (Fundo de Garantia por Tempo de Serviço), numa racionalidade com vistas à redução de ônus sobre o erário (AZEVEDO, 1988), para fugir da dependência de uma única fonte de financiamento.

O BNH também iria estimular o mercado de trabalho, contribuir no desenvolvimento da indústria de material de construção e fortalecer as empresas de construção civil e das atividades associadas. Com o tempo, ao agregar o financiamento das atividades de saneamento básico, de materiais de construção e transporte, dentre outros, o BNH foi transformado em um banco de desenvolvimento urbano (AZEVEDO, 1988).

Apesar de ser um bem indispensável para a reprodução da vida, a habitação, no modo de produção da economia de mercado, como qualquer outro bem, se converte em mercadoria (SILVA; 
TOURINHO, 2015). A realidade mostrou que os objetivos sociais e econômicos não eram harmoniosos e nem coerentes entre si, o que fez com que as camadas de menor renda fossem as menos beneficiadas pelo BNH, por não conseguir arcar com os custos dos serviços (AZEVEDO, 1988).

O Estado utilizou a política habitacional para controlar as classes trabalhadoras, neutralizando os movimentos urbanos que começaram a exsurgir no país, ao mesmo tempo em que começou a praticar atos que violentavam o direito à cidade, como a prática de remoção de favelas (COSTA, 2017).

Deste modo, o BNH passou então a concentrar o financiamento e a atividade de planejamento do desenvolvimento urbano no âmbito federal, com metas de produção nos setores de habitação e de saneamento para a execução de projetos de implantação de redes de água e esgoto e de construção de moradias (ARRETCHE, 1996).

Um dos equívocos desta política foi voltar seus recursos para a construção da casa própria pelo sistema formal da construção civil, sem estruturar qualquer ação significativa para apoiar, do ponto de vista técnico e financeiro, a produção de moradia ou urbanização por processos alternativos, que incorporasse o esforço próprio e capacidade organizativa das comunidades, o que gerou um intenso processo de urbanização informal, em assentamentos urbanos precários (BONDUKI, 2008).

Como o governo federal concentrava os recursos financeiros, para os municípios terem acesso ao capital deviam se submeter as suas regras, que incluíam a existência de legislação urbanística. Ocorre que estes documentos eram feitos apenas por serem obrigatórios, para justificar investimentos setoriais, paralelos e externos à gestão local, que disponibilizavam as escassas áreas urbanizadas da cidade para os produtos imobiliários de classe média (ROLNIK, 2009, p. 33). De todo modo, nota-se que a política habitacional serviu para estimular a economia e o mercado da construção civil.

Para Bonduki (2008), a despeito dos problemas, a importância do BNH é indiscutível para a história da política de habitação, pois este período foi o único em que o país teve, de fato, uma Política Nacional de Habitação. Ainda assim, a opção pela construção de grandes conjuntos na periferia das cidades, a desarticulação entre os projetos habitacionais e a política urbana e a desconsideração pela qualidade do projeto, gerando soluções uniformizadas, sem preocupação com a qualidade da moradia e com a inserção urbana (BONDUKI, 2008). 
Na década de 1970, com a desaceleração da economia, mudanças na ordem econômica e com a crise fiscal pela qual passaram diversos países ao redor do globo, houve uma corrosão da capacidade estatal de manter o custo do Estado de Bem-estar Social, com o desencadeamento de reformas no sentido de reduzir o tamanho do Estado, descentralizar a gestão, transferência de atribuições e desregulação (ARRETCHE, 1996).

A Reforma do Estado experimentada por diversos países ao redor do globo, incluindo o Brasil, fez com que houvesse um deslocamento da agenda pública, que em conjunto com ideais democráticos de participação social na gestão pública e transparência, impulsionou o interesse em políticas públicas e ação governamental (TREVISAN; BELLEN, 2008).

O BNH foi extinto em 1986, tendo sido incorporado à Caixa Econômica Federal, que o sucedeu em seus direitos e deveres. Mas os efeitos desta política, ou melhor, da visão na qual a política habitacional foi baseada, são perceptíveis atualmente nas cidades brasileiras, em que se constata que parte da população tem acesso aos recursos urbanos de qualidade e outra parte é excluída da fruição destes bens.

No período de redemocratização emergiram movimentos sociais urbanos, como o Movimento Nacional de Reforma Urbana, que possuíam uma nova agenda e conquistaram a institucionalização de regras formais que endossavam a descentralização política, com a distribuição de competências aos municípios, e instrumentos de participação social na definição do rumo da política urbana (KLINTOWITZ, 2015).

Com o advento da Constituição Federal de 1988, foi criado um capítulo sobre política urbana em seus artigos 182 e 183 e os municípios foram reconhecidos como os entes federados responsáveis pela condução do planejamento urbano local.

Mas os atores que representavam o setor produtivo da construção civil e mercado imobiliário, que tinham proeminência na política anterior, não foram eliminados, mantendo-se como relevantes agentes e conformando sua agenda com a dos movimentos sociais, o que permitiu a coexistência de interesses paralelos e conflitantes (KLINTOWITZ, 2011).

Com a redemocratização, também se abriu um pequeno espaço para a uma gestão democrática voltada para habitação de interesse social, mas que durante meados da década de 1990 acabou retomando a priorização na regulação dos recursos financeiros onerosos visando melhor desempenho do mercado (MARICATO, 1998)

Além disso, do ponto de vistas da estrutura pública administrativa, entre a extinção do BNH 
em 1986 e a criação do Ministério das Cidades em 2003, o setor do governo federal responsável pela política habitacional esteve subordinado a sete ministérios ou estruturas administrativas diferentes, caracterizando descontinuidade e ausência de estratégia para enfrentar o problema de déficit habitacional (BONDUKI, 2008, p. 75-76), o que se manteve com a extinção do Ministério das Cidades em 2019, que teve suas atribuições incorporadas no Ministério do Desenvolvimento Regional.

Isto se refletiu no Sistema Nacional de Habitação de Interesse Social, criado pela Lei n.으 11.124/2005 e se estruturou no programa habitacional Minha Casa Minha Vida (PMCMV), criado em 2009 (Lei n. 11.977/2009), em que se constata o estabelecimento de princípios e objetivos que afirmam a obrigação de viabilizar para a população de menor renda o acesso à terra urbanizada e à habitação digna e sustentável (art. 2ํ, II, Lei n.o 11.124/2005) ou de financiar moradias nas áreas urbanas para famílias classificadas de baixa renda (art. 1ํ, caput, Lei n.o 11.977/2009), mas que não prevê instituições que assegurem, na prática, que as necessidades habitacionais das cidades brasileiras sejam atendidas.

Em 2008, um ano antes da criação do PMCMV, houve uma crise internacional no mercado, que afetou o setor da construção civil, o que evidencia que um dos objetivos deste programa estava mais próximo aos seus interesses, de aquecer o mercado imobiliário e não ser afetado pela conjuntura econômica, do que dos movimentos sociais, de reformar as cidades.

Na mesa de negociação do Sistema Nacional de Habitação de Interesse Social foram chamados os mais diferentes players, desde o Ministério das Cidades (art. 5으, I, Lei n.o 11.124/2005), passando pela Caixa Econômica Federal (art. 5ㅇ, III, Lei n. 11.124/2005), por conselhos de representação estadual e municipal (art. 5o, V, Lei n.ำ 11.124/2005), até agentes financeiros (art. 5으, VIII, Lei n.ำ11.124/2005), o que exigiu a coordenação entre o setor público e privado e entre as diferentes esferas da Federação.

Para Klintowitz (2015), as metas do PMCMV por faixa de atendimento pouco dialogam com o déficit habitacional por faixa de renda, pois enquanto o maior deficit habitacional estava concentrado na faixa de renda até 3 salários mínimos, proporcionalmente as faixas de renda mais altas foram as mais beneficiadas.

De forma sintética, quanto ao quadro nacional, pouco se avançou para democratizar o acesso ao solo urbano e garantir moradias dignas, pois os municípios, mesmo no contexto de descentralização política, ficam reféns do financiamento da União e as arenas participativas locais possuem pouco poder efetivo de escolha (ROLNIK; IACOVINI; KLINTOWITZ, 2014). 
Ademais, não se enfrenta chamado déficit qualitativo das necessidades habitacionais, formado por moradias que apresentam deficiências no acesso à infraestrutura ou adensamento excessivo, que necessitam de intervenções para condições dignas para sua habitação e não, necessariamente, de moradias novas (BONDUKI, 2008).

Ou seja, não se trata de apenas construir novas residências, mas de programas e ações que articulem políticas urbana, fundiária e de saneamento, o que exige alguma participação do Poder Público, mesmo que em parceria com o setor privado.

Por fim, existem imóveis vagos e depreciados em locais urbanizados e que contam com infraestrutura, em geral nas áreas centrais e consolidadas das maiores cidades, cuja utilização poderia amenizar o problema de famílias necessitadas de moradia (BONDUKI, 2008). A adoção de medidas desta poderia reduzir a segregação socioespacial nas urbes.

Ao retratar o quadro vivenciado nas cidades Bonduki (2016, p. 80) afirma que as necessidades habitacionais cresceram, os aluguéis e o valor da terra explodiram e a crise de mobilidade aumentou, a universalização do saneamento não foi alcançada; empreendimentos imobiliários segregados se multiplicam, junto com a supressão de áreas verdes, e a população de baixa renda e parte da classe média não conseguiu se manter em localizações adequadas.

Tudo isto num contexto político que convive com procedimentos seculares caracterizados pela privatização da esfera pública e pelo patrimonialismo, com vistas ao atendimento de interesses clientelistas de governantes e de proprietários urbanos (MARICATO, 1998, p. 1-2)

É necessário articular a problemática acerca da política urbana, com suas implicações políticas, pois seu resultado é contingente e depende das suas interações no jogo político.

\section{RESULTADOS}

Com o institucionalismo histórico é possível realizar adaptações para a análise da política nacional, ou ainda mais focada em uma região. Em resumo, em toda a trajetória nacional, os programas habitacionais tendem a transferir o protagonismo de sua efetivação ao mercado imobiliário (construtoras e incorporadoras), que possui autonomia excessiva no desenvolvimento do projeto e execução das unidades habitacionais, sem haver, necessariamente, correspondência com os interesses sociais. 
Usando como base o modelo apresentado na proposta metodológica, a aplicação da matriz adaptada de Pereira, Lima e Machado (2018) leva ao seguinte quadro de análise.

Quadro 3. Aplicação da matriz de análise para o estudo da política habitacional.

\begin{tabular}{|c|c|c|c|}
\hline $\begin{array}{l}\text { Dimensões } \\
\text { de análise }\end{array}$ & Período 1940 a 1964 & 1964 a 1985 & 1985 até os dias atuais \\
\hline Contexto & $\begin{array}{l}\text { Centralização política e } \\
\text { econômica na União, } \\
\text { final da Era Vargas e } \\
\text { posterior } \\
\text { redemocratização } \\
\text { Industrialização e } \\
\text { urbanização }\end{array}$ & $\begin{array}{l}\text { Centralização política e } \\
\text { econômica na União } \\
\text { Governo Militar } \\
\text { Urbanização }\end{array}$ & $\begin{array}{l}\text { Descentralização política } \\
\text { Concentração de } \\
\text { recursos na União } \\
\text { Redemocratização }\end{array}$ \\
\hline $\begin{array}{l}\text { Trajetória da } \\
\text { política } \\
\text { habitacional }\end{array}$ & $\begin{array}{l}\text { Subsídios para financiar } \\
\text { a habitação com } \\
\text { orçamento federal } \\
\text { Não há relação entre } \\
\text { política urbana e política } \\
\text { habitacional }\end{array}$ & $\begin{array}{l}\text { Subsídios para financiara } \\
\text { habitação e o } \\
\text { desenvolvimento urbano } \\
\text { no âmbito federal com } \\
\text { orçamento federal e } \\
\text { captação de poupança } \\
\text { livre e compulsória } \\
\text { (FGTS) } \\
\text { Não há relação entre } \\
\text { política urbana e política } \\
\text { habitacional }\end{array}$ & $\begin{array}{l}\text { Subsídios para financiara } \\
\text { habitação e o } \\
\text { desenvolvimento urbano } \\
\text { no âmbito federal com } \\
\text { orçamento federal e } \\
\text { captação de poupança } \\
\text { livre e compulsória } \\
\text { (FGTS) } \\
\text { Há relação entre política } \\
\text { urbana e política } \\
\text { habitacional nas regras } \\
\text { formais }\end{array}$ \\
\hline $\begin{array}{c}\text { Condicionant } \\
\mathrm{e}\end{array}$ & $\begin{array}{l}\text { Tentativa de legitimar o } \\
\text { Governo por meio da } \\
\text { política habitacional } \\
\text { Atores do segmento da } \\
\text { construção civil têm seus } \\
\text { interesses atendidos e } \\
\text { pessoas com conexão } \\
\text { política são beneficiadas } \\
\text { pelo programa } \\
\text { habitacional } \\
\begin{array}{l}\text { Fundação da Casa } \\
\text { Popular fornece } \\
\text { subsídios para aquisição } \\
\text { de moradia }\end{array}\end{array}$ & $\begin{array}{l}\text { Atores do segmento da } \\
\text { construção civil têm seus } \\
\text { interesses atendidos e } \\
\text { pessoas de classe média } \\
\text { são beneficiadas pelo } \\
\text { programa habitacional } \\
\text { Banco Nacional da } \\
\text { Habitação fornece } \\
\text { subsídios para aquisição } \\
\text { de moradia e outras } \\
\text { políticas urbanas }\end{array}$ & $\begin{array}{l}\text { Atores de movimentos } \\
\text { sociais em favor da } \\
\text { Reforma Urbana e atores } \\
\text { do segmento da } \\
\text { construção civil têm seus } \\
\text { interesses atendidos, } \\
\text { ainda que sejam } \\
\text { contraditórios } \\
\text { A maior redução do } \\
\text { déficit habitacional se } \\
\text { concentra nas maiores } \\
\text { faixas de renda } \\
\text { Caixa Econômica Federal } \\
\text { fornece subsídios para } \\
\text { aquisição de moradia }\end{array}$ \\
\hline
\end{tabular}

Fonte: Modelo adaptado de Pereira, Lima e Machado (2018).

A principal mudança no período da redemocratização a partir de 1985 é que os movimentos sociais ganharam destaque, no entanto, sem constituir uma efetiva ruptura com o legado deixado 
pelo sistema anterior. A coordenação que existe entre as diferentes esferas da Federação caminha mais no sentido de atender à demanda do setor imobiliário, do que da agenda da Reforma Urbana.

Em toda esta trajetória o que se nota como uma constante é que são poucos os contemplados com a política e que atores do mercado têm utilizado as instituições vigentes em seu favor, aproveitando a contingência do momento e opondo-se às mudanças abruptas. Por exemplo, é criada uma política nacional de habitação com princípios e objetivos progressistas, recursos são destinados aos programas sociais, o que acomoda os interesses dos movimentos sociais. Contudo, as principais decisões são tomadas por agentes econômicos mais interessados no lucro, do que em benefícios sociais, em detrimento da população, que não participa do processo com capacidade de agente.

A ausência de controle estatal sobre as políticas habitacionais fez com que moradias fossem produzidas conforme a lógica de mercado, em espaços precificados que transformam tanto o espaço urbano quanto as habitações em mercadorias, que tem como subproduto, nos locais em que o mercado não alcança, a formação de ocupações precárias e informais, onde não há direito à cidade (MASTRODI; ZACCARA, 2016).

Logo, a despeito da existência de novos pontos de escolha, representados por novos regimes, os arranjos institucionais tendem a autorreforçar a escolha inicial desde a Era Vargas, passando pela redemocratização, Governo Militar, nova redemocratização de 1985, que permite travar ou atrasar mudanças institucionais, mantendo uma razoável estabilidade, em favor dos interesses do segmento da construção civil. Ou seja, mudou-se o nome da organização, mudaram as regras, mas a lógica é a mesma (SILVA; TOURINHO, 2015).

Se a mudança irá depender de como os atores, em especial as organizações, irão se aliar e complementar para transformar as regras formais de acordo com a existência de incentivos seria possível atuar no âmbito local para que criar regras formais condizentes com o objetivo de democratizar o acesso ao solo. Mas o que a literatura tem apontado é que pouco é feito no âmbito municipal para mudar o quadro (ROLNIK, 2009; ROLNIK; IACOVINI; KLINTOWITZ, 2014).

Assim, algumas condições para mudar esta herança podem ser sistematizadas em:

1) Além dos objetivos e princípios, a política de habitação deve prever critérios mais rígidos para a transferência dos recursos aos agentes econômicos, alinhados com requisitos concretos do planejamento urbano local; 
2) Incentivos à participação popular para tomar o protagonismo nas decisões que estão a critério dos agentes econômicos.

Apesar de parte dos resultados estarem alinhados com trabalhos realizados (KLINTOWITZ, 2015), o modelo adotado traz mais instrumentos de compreensão da realidade para buscar a alteração na trajetória da política. O resultado também reforça a ideia de que mesmo que haja um arcabouço legislativo federal, a utilização de diversos instrumentos urbanísticos depende de previsão nos planos diretores municipais, elaborados pelas prefeituras e aprovados pelos legislativos (BONDUKI, 2008).

Ademais, o fato é que a iniciativa privada possui atores que têm agido ao longo das décadas para ter seu espaço na implementação da política urbana e a trajetória nacional indica que uma mudança endógena pode não ser viável se a tentativa for uma ruptura completa com o modelo vigente.

Em resumo, não se alterou o modelo tradicional de intervenção sobre as cidades, apesar de um esforço no sentido de possibilitar a inclusão urbana dos mais pobres (BONDUKI, 2016, p. 81). $\mathrm{O}$ aumento da população urbano levou à produção doméstica ou informal da moradia, com ocupação de terra ou de lote clandestino, complementada pela autoconstrução da moradia, que permite a existência de um mercado excludente e especulativo (MARICATO, 1998).

Logo, assim como existem atores privados, existe uma parcela da população que produziu e reproduziu suas formas de vivência social, sob regras formais e informais, e que não deve ser tratada como invasora ou sujeita à remoções forçadas, olvidando que o Estado tem sido omisso e permitido a construção bairros e cidades sob a vigência de regras informais.

Portanto, mudanças pontuais que coloquem a população no centro do debate diminuem a influência de atores econômicos, mas não os anulam. E a adoção de regras mais rígidas de planejamento urbano irão influenciar o comportamento das empresas para, por vontade própria ou por vontade do Poder Público, atenderem ao interesse público e coletivo de construir cidades mais humanas.

\section{CONCLUSÃO}


O modelo proposto para a análise da política habitacional deixou evidente que a interação entre os atores permitiu a definição de uma trajetória, relativamente estável, com mudanças incrementais, desde a década de 1940.

Por um lado, houve um progressivo processo de descentralização e municipalização de competências sobre gestão urbana, com incentivo à participação popular e institucionalização de regras em favor da inclusão social, potencializado a partir da redemocratização na década de 1980, com a atuação de movimentos em prol da Reforma Urbana. Do outro, a União concentra recursos e define regras para os municípios terem acesso a eles, acomodando interesses econômicos dos atores do setor da construção civil, sem preocupação com a efetiva proteção social da população, desde a década de 1940.

Ao longo da história decisões foram tomadas e a opções disponíveis no momento subsequentes foram reduzidas, com altos custos de reversão ou mudança. A política habitacional é desenhada por conhecimento técnico e escolhas políticas que evidencia a assimetria de poder dos atores. Novas pesquisas são essenciais para debater o assunto para a construção de alternativas para mudar o porvir.

\section{REFERÊNCIAS}

ANITELLI, F.; TRAMONTANO, M. Abordagens incomuns na política habitacional brasileira: Reabilitação de edifícios ociosos e sua conversão em habitação de interesse social. Cidades, Comunidades e Territórios, v. 32, p. 40-50, jun. 2016.

AZEVEDO, S. Vinte e dois anos de política de habitação popular (1964-86): criação, trajetória e extinção do BNH. Revista de Administração Pública, v. 22, n. 4, 1988.

BONDUKI, N. Uma nova agenda de desenvolvimento urbano é possível? Um olhar a partir do Brasil. In: BALBIM, R. Geopolítica das cidades: velhos desafios, novos problemas. Brasília: Ipea, 2016, p. 77-96.

. Política habitacional e inclusão social no Brasil: revisão histórica e novas perspectivas no governo Lula. Arq. urb, n. 1, p. 70-104, 2008.

CAPOCCIA, G. When do institutions "bite"? Historical institutionalism and the politics of institutional change.Comparative Political Studies, v. 49, n. 8, p. 1095-1127, 2016.

.; KELEMEN, D. The Study of Critical Junctures: Theory, Narrative, and Counterfactuals in Historical Institutionalism. World Politics, v. 59, n. 3, p. 341-369, abr.2007. 
COSTA, S. S. Crise econômica, provisão habitacional e a (des) construção do Direito à cidade no período BNH. Revista de Direito da Cidade, v. 9, n. 2, p. 754-771, 2017.

GÖTTEMS, L. B., et al. Trajetória da política de atenção básica à saúde no Distrito Federal, Brasil (1960 a 2007): análise a partir do marco teórico do neo-institucionalismo histórico. Caderno Saúde Pública, Rio de Janeiro, v. 25, n. 6, p. 1409-1419, jun. 2009.

LASWELL, H. D. Politics: Who Gets What, When, How. Cleveland: Meridian Books, 1936.

LEFEBVRE, H. O direito à cidade. São Paulo: Centauro, 2001.

HALL, P.; TAYLOR, R. Political science and the three new institucionalism. Political Studies, v. 44, p. 936-957, 1996.

IBGE. Brasil em síntese. 2018. Disponível em: https://cidades.ibge.gov.br/brasil.Acessoem: 10 mai. 2019.

IMMERGUT, E. The Theoretical Core of the New Institutionalism. Politics \& Society, v. 26, n. 01, p. 5-34, 1998.

. Historical-Institutionalism in Political Science and the Problem of Change. In: WIMMER, Andreas; KÖSSLER, Reinhart (Ed.). Understanding Change: Models, Methodologies, and Metaphors.New York/Basingstoke: Palgrave/Macmillan, p. 237-259, 2006.

KLINTOWITZ, D. C. Entre a Reforma Urbana e a Reforma Imobiliária. 256 f. Tese (Doutorado) Escola de Administração de Empresas de São Paulo da Fundação Getúlio Vargas, 2015.

Como as políticas habitacionais se inserem nos contextos de Reforma do Estado? A experiência recente do Brasil. Revista Pensamento \& Realidade, v. 26, n. 3, p. 101-120, 2011.

MACEDO, R.; CKAGNAZAROFF, I. Neo-institucionalismo: Discussão acerca da teoria esuas vertentes. Revista da Universidade Vale do Rio Verde, v. 16, n. 1, p. 1-10, 2018.

MARCH, J.; OLSEN, J. The new institucionalism: Organizational factors in political life. The American Political Science Review, Denton, v. 78, n. 3, p. 734-749, set. 1984.

MARICATO, E. . Política urbana e de habitação social: um assunto pouco importante para o governo FHC. Revista Praga, São Paulo: Hucitec, v. 1, n.6, p. 67-78, 1998.

MASTRODI, J.; ZACCARA, S. M. L. S. O que é o objeto "moradia" do Programa Minha Casa Minha Vida? Revista de Direito da Cidade, v. 8, n. 3, p.859-885, 2016.

MOREIRA, T. A.; RIBEIRO, J. A. A questão fundiária brasileira no desenho das políticas nacionais de habitação:considerações a partirdo início do século XXI. Cadernos Metrópole, v. 18, n. 35, p. 1531, abr. 2016.

NASCIMENTO NETO, P.; et al. Análise de políticas públicas: entre a modelagem e a realidade da política habitacional brasileira. Revista Administração Pública, Rio de Janeiro v. 49, n. 4, p. 847868, jul.-ago. 2015. 
OUTEIRO, G. M.; NASCIMENTO, D. M. Direito humano à moradia e a regularização fundiária na Amazônia: limites e possibilidades. Pensar - Revista de Ciências Jurídicas, v. 21, n. 2, p. 507-533, 2016.

OUTEIRO, G. M. Um Estudo Histórico-Institucional do Programa Terra Legal de Regularização Fundiária na Amazônia. REVISTA ESTUDOS INSTITUCIONAIS, v. 5, n. 2, p. 559-585, 2019.

SANTOS, A. P.; DUARTE, S. Política habitacional no Brasil: uma nova abordagem para um velho problema. RFD-Revista da Faculdade de Direito da UERJ, n. 18, 2010.

PEREIRA, A. M.; LIMA, L.D.; MACHADO, C. V. Descentralização e regionalização da política de saúde: abordagem histórico-comparada entre o Brasil e a Espanha. Ciência \& Saúde Coletiva, v. 23, n. 7, p. 2239-2251, 2018.

PERES, P. Comportamento ou instituições? A evolução histórica do neoinstitucionalismo da Ciência Política. Revista Brasileira de Ciências Sociais, São Paulo, v. 23, n. 68, p. 53-71, out. 2008.

ROLNIK, R.; IACOVINI, R. F. G.; KLINTOWITZ, D. Habitação em municípios paulistas: construir políticas ou "rodar" programas? R. B. Estudos urbanos e regionais, v.16, n.2, p.149-165, nov. 2014.

ROLNIK, R. Democracia no fio da navalha limites e possibilidades para a implementação de uma agenda de reforma urbana no brasil. R. B. Estudos urbanos e regionais, v.11, n.2, nov. 2009.

SILVA, M. L.; TOURINHO, H. L. O Banco Nacional de Habitação e o Programa Minha Casa Minha Vida: duas políticas habitacionais e uma mesma lógica locacional. Caderno Metrópole, vol.17 n.34, Nov. 2015.

SILVA, V. Fundamentos do Institucionalismo na Teoria Social de Thorstein Veblen. Política \& Sociedade, Florianópolis, v. 9, n. 17, p. 289 -323, out. 2010.

SKOCPOL, T.; PIERSON, P. Historical Institutionalism in contemporary Political Science. In: KATZNELSON, I., MILNER, H. Political Science: State of the Discipline.New York: W.W. Norton, p. 693-721, 2002.

SOTO, L. G. Una revisión de los aportes del institucionalismo histórico a la ciencia política. Revista Colombiana de CienciasSociales, v. 7, n. 1, p. 224-241, 2016.

SOUZA, C. Políticas públicas: uma revisão da literatura. Sociologias, Porto Alegre, ano 8, no 16, p. 20-45, jul/dez 2006.

STEINMO, S. What is Historical Institutionalism. In: DELLA PORTA, D.; KEATING, M. Approaches in the Social Sciences. Cambridge: Cambridge University Press, p. 150-178, 2008.

THELEN, K. Historical Institutionalism in Comparative Politics. Annual Review of Political Science, v. 2, p. 369-404, 1999.

THÉRET, B. As instituições entre as estruturas e as ações. Lua Nova, São Paulo, n. 58, p. 225-255, 2003. 
TREVISAN, A.; BELLEN, H. M. Avaliação de políticas públicas: uma revisão teórica de um campo em construção. Revista de Administração Pública, Rio de Janeiro, v. 42, n. 3, p. 529-50, maio/jun. 2008.

VEBLEN, T. The Instinct of Workmanship and the State of Industrial Arts. New Brunswick: Transaction Publishers, 1989.

Trabalho enviado em 26 de março de 2020

Aceito em 08 de maio de 2020 